Revista Iberoamericana, Vol. LXXV, Núm. 226, Enero-Marzo 2009, 217-227

\title{
LA DESESTABILIZACIÓN DE LOS CONSTRUCTOS BINARIOS EN WASLALA, DE GIOCONDA BELLI
}

POR

Alice J. Poust

Bucknell University

En su tercera novela, Waslala (1996), Gioconda Belli plantea la doble búsqueda de la utopia y de la razón de ser en una tierra centroamericana problematizada y postergada por las naciones más poderosas del mundo. Belli sitúa su novela en el ficticio Faguas, nombre que simultáneamente disimula y evoca a su país natal de Nicaragua. ${ }^{1}$ En esta obra, la joven protagonista, Melisandra, aprovecha la llegada al Río San Juan de un grupo de viajeros internacionales, con rumbo al interior del país, para emprender la búsqueda de la utópica Waslala, el posible paradero de sus padres, a quienes no ha visto desde su infancia. A través de su narración de este viaje compartido por la protagonista nicaragüense con dos mujeres holandesas y un periodista y un científico, ambos de Estados Unidos, entre otros, Belli crea una serie de oposiciones binarias asociadas con la historia del pensamiento crítico sobre la literatura/cultura latinoamericana -utopía/distopía, civilización/ barbarie, patriarcado/matriarcado, colonia/nación, hegemonía/subalternidad-, simultáneamente efectuando la desestabilización de estos constructos.

Las mismas fronteras desleídas de esta nación centroamericana anuncian la inestabilidad de las líneas divisorias entre las cosas y los conceptos que presenta Belli. Faguas es un estado amorfo, sin un gobierno nacional en funciones, sin infraestructura económica y casi sin centros urbanos. La ubicación temporal de Waslala en el futuro, a mediados del siglo xxı, le sirve a Belli para crear una realidad en que las luchas y las oposiciones entre los elementos de civilización y

1 La primera novela de Belli, La mujer habitada (1988), se sitúa también en el ficticio país de Faguas. La obra poética de Belli, desde Sobre la grama (1972) a El ojo de la mujer (1990), resalta la agencia de la mujer tanto en el amor como en la vida política de la nación. El tema autobiográfico, presente en gran parte de su obra en poesía y narrativa, ocupa primera plana en El país bajo mi piel. Memorias de amor y guerra (2001), donde Belli escribe sobre su participación en la vida política de Nicaragua y sobre su vida personal y familiar. Su celebración del amor erótico como manifestación del sentido de la plenitud vital, junto con su espíritu humanista, constantes en su obra, se entrelazan en su más reciente publicación, la novela histórica: El pergamino de la seducción (2005), sobre la figura de Juana la Loca. 
barbarie, o entre hegemonía y subalternidad, se han "resuelto" de manera definitiva: Faguas y su entorno centroamericano asumen la identidad de una "barbarie” ya no en un debate con la "civilización” sino relegada por las sociedades más pudientes del mundo, autodenominadas las “civilizadas”, a la inferioridad perpetua. Al desestabilizar la oposición de elementos binarios, tan frecuente en el pensamiento crítico e ideológico de Occidente, Belli nos introduce en una realidad llena de confusiones y contradicciones, en la que, sin embargo, los personajes se ven obligados a actuar en consecuencia con sus decisiones éticas. Dado el fracaso de la dialéctica, Belli recurre a una vision humanista, depositando su esperanza para el futuro en la humanidad de los individuos heroicos que se solidarizan con los pueblos oprimidos o subalternos.

En el orden mundial de mediados del siglo xxi, el mundo “civilizado” no plantea ya la lucha contra "la barbarie", sino que procura evitarla y mantenerla aislada. Faguas es considerada

insalubre[s], un virus maligno que amenazaba, con su mera existencia, la vida civilizada, avanzada, afanada ahora con la idea de la exploración espacial, de emigrar en masa y empezar de nuevo en otra galaxia donde no se filtrara nunca por ninguna ranura la noción de otros seres humanos subsistiendo en condiciones primitivas, míseras, reproduciendo su pobreza, sus guerras, sus plagas sin control. (23)

Faguas ha perdido su soberanía y su capacidad de autodeterminación, si es que alguna vez las poseyó. Los países hegemónicos del mundo deciden los términos de su relación con esta tierra centroamericana: las exigencias de las economías desarrolladas requieren la exportación de las pocas materias primas que le quedan a Faguas tras la explotación colonial y capitalista; al mismo tiempo, la preocupación del “primer mundo” por el oxígeno tiene como resultado la prohibición de cortar árboles en Faguas; el consumismo de los países hegemónicos lleva a un "acuerdo" según el que ciertas zonas de Faguas deben servir de depósitos de la basura generada en las sociedades de consumo. En un mundo que las telecomunicaciones han hecho más pequeño, los lugares como Faguas, sin estar lejos de los países avanzados, ocupan los espacios definidos como marginales.

El juego de Belli con los conceptos de centro/margen y civilización/barbarie se ve en el hecho de que en Faguas los personajes más representativos de "la civilización” son los que viven marginados. Los abuelos de Melisandra, Don José, un autodenominado “enamorado de la civilización, de los progresos del hombre, de las letras” (34), y Doña María, una mujer independiente, activa y progresista, han tenido que alejarse de la ciudad y de la vida pública que ésta representa para dedicarse a “cultivar su jardín” en la zona neutral conocida como “El Río”, una referencia al Río San Juan, a un día de navegación de Greytown. Es significativo que hayan ido 
a vivir cerca de la costa del Atlántico y lejos de la ciudad Cineria, en el interior, donde el poder de facto del país está en manos de los hermanos Espada, reputados traficantes de drogas y armas. Así, en su autoexilio en un espacio “fronterizo”, Don José recibe noticias de la civilización occidental a través de viajeros europeos y norteamericanos. Sus referentes intelectuales son poetas norteamericanos y europeos, tales como Dante, Thomas More y Whitman. En este sentido, el ideal de civilización y, hasta cierto punto, la idea de la utopía se remontan, para Don José, a la tradición europea. El exilio virtual de Don José, ya viudo, se mantiene en gran parte por los esfuerzos de los Espada, quien es gracias a la falta de un gobierno auténtico se han apoderado de gran parte del interior o del centro del país. La violencia implícita en su apellido y sus negocios basados en el tráfico de armas y drogas los identifica con la barbarie. Al mismo tiempo, la pertenencia de Don José a la elite intelectual del pasado reciente de Faguas, y las fuentes de su pensamiento en tradiciones que participan del imperialismo y colonialismo que han afligido a su país, y pueden contribuir también a su marginación en esta novela. La ambigüedad que muestra Belli con respecto al pensamiento utópico de Occidente sugiere que le puede interesar nadar en las aguas del pensamiento subalterno, pero guardando la ropa que le sirve de la tradición occidental, sobre todo del humanismo. ${ }^{2}$

Aunque el ideal de la utopía no es completamente autóctono, como hemos visto, se ha arraigado en Faguas; en varias ocasiones los fagüenses de distintas capas sociales hablan de la comunidad utópica llamada Waslala como algo propio y añorado (Waslala 111-14). Como indica Barbara Droscher (159), el viaje que emprende Melisandra hacia el interior del país combina la búsqueda de la utopía con la de sus padres de quienes no ha sabido nada desde el viaje de éstos a Waslala veinte años atrás. Las credenciales genealógicas de Melisandra (su abuelo fue uno de los fundadores de la utópica Waslala) la convierten en la persona idónea para llevar a cabo esta búsqueda, según las creencias populares.

La ciudad de Cineria, por donde Melisandra tiene que pasar en su viaje, es emblema de la distopía de Faguas, en contraste con la utópica Waslala, aunque la relación entre las dos comunidades es más compleja que la simple oposición. La formulación de Belli es consonante con la opinión del crítico Fredric Jameson, quien arguye en contra de la relación oposicional de utopía y distopía. En cierto modo, Belli deshace la posible relacion oposicional utopía/distopía al situar Waslala dentro de la distópica nación de Faguas y al hacer que Melisandra tenga que pasar por Cineria para llegar a Waslala. El argumento de Fredric Jameson sobre la diferencia

2 Es evidente el cariño que tiene Belli por la figura de Don Quijote como representante del idealismo utópico y del espíritu humanista de Cervantes. La insistencia de Belli en la importancia de la imaginación en la tentativa humana por crear un mundo mejor refleja su propio humanismo cultural, que reclama para las culturas latinas o hispánicas la facultad y la potencia imaginativa. 
no-oposicional de utopía y distopía se corresponde estrechamente con el tratamiento de Belli con respecto a Cineria y Faguas, en general, y a la comunidad utópica de Waslala. Jameson afirma que "the dystopian is generally a narrative, which happens to a specific subject or character, whereas the Utopian text is mostly nonnarrative" (55-56). La novela Waslala es precisamente esa narrativa de lo que le "pasa" a Melisandra y a sus compañeros. Aunque la madre de Melisandra le ofrece a su hija un breve resumen de la historia de la comunidad de Waslala, y en teoría podría haber una narración más extendida al respecto, esta narración no se presenta. El hecho de que los "padres" de la comunidad de Waslala fueran poetas también refuerza la distinción genérica entre la poética Waslala y la narrativa de Waslala.

Otras consideraciones ofrecidas por Jameson sobre la diferencia entre la distopía y la utopía encajan con el planteamiento novelesco de Belli:

[...] the dystopia is always and essentially what in the language of science-fiction criticism is called a "near-future" novel: it tells the story of an imminent disaster -ecology, overpopulation, plague, drought, the stray comet or nuclear accidentwaiting to come to pass in our own near future [...] But the Utopian text does not tell a story at all; it describes a mechanism or even a kind of machine, it furnishes a blueprint rather than lingering upon the kinds of human relations that might be found in a utopian condition [...] Mostly, however, they [utopian texts] carefully noted down the precise mechanisms whose construction alone would render those relations and pleasures, those scenes, possible. For the ideals of Utopian living involve the imagination in a contradictory project (56)

De hecho, la narración de Waslala se corresponde a la descripción que hace Jameson de la distopía en cuanto a su pertenencia a un tiempo futuro, con su planteamiento de posibles desastres ecológicos y la realidad que experimentan los fagüenses y demás personajes. De la misma manera, Waslala, como utopía, existe más como logro fugaz y proyecto posible para la imaginación humana, según la formulación de Belli. En cuanto a la estructura de la novela, claramente, la utopía está encapsulada en la narrativa distópica. La historia de las experiencias de los personajes, la marginación de Faguas, y la crisis ecológica, las cuales se asocian con lo distópico, según Jameson, constituyen la mayor parte de la narración. Aunque los ideales de Waslala son descritos en la novela, y la madre de Melisandra le presenta los anales de Waslala a su hija al final de la obra, lo que toca a la utopía queda marginado en la narración.

Cineria, la antigua capital del país, contrasta marcadamente con el ideal utópico, acercándose más bien a la idea de "la barbarie”. Es una ciudad en plena descomposición tras años de guerra civil, y vive bajo la amenaza de los hermanos Espada, que ejercen el poder político y militar en la zona. La mayoría de su población 
está desempleada (Waslala 158) y los juegos de azar y la prostitución producen el único modus vivendi para muchos (157). Algunos habitantes viven directa o indirectamente del mercado negro y del tráfico de la droga filina, controlados por los hermanos Espada. A las afueras de la ciudad, los comunitaristas, los únicos que se atreven a mantener cierta independencia frente a los Espada, llevan la "industria" de la basura. Ante la falta de posibilidades económicas, los comunitaristas han llegado a un acuerdo con empresas transnacionales para recibir la basura de los países desarrollados. Rescatan muchos objetos de la basura, los clasifican, y los venden o intercambian en un mercado o bazar. Lo que no se puede utilizar se quema, contribuyendo así a la contaminación del área. Así, Cineria sufre de corrupción política (los Espada) y de contaminación ambiental (de la basura traída por los comunitaristas). La situación se deteriora aún más con el secuestro de Melisandra por parte de los Espada y con la llegada de desechos tóxicos metidos entre el resto de la basura, que lleva a la contaminación mortal de la líder de los comunitaristas, Engracia, junto con los jóvenes que trabajan a su lado.

La especulación de Gioconda Belli sobre el futuro de Centroamérica, con la evocación correspondiente de temas como el de civilización y barbarie o el de utopía y distopía, se extiende también al papel desempeñado por las mujeres en la nueva sociedad latinoamericana. Al centrarse en la experiencia de una protagonista femenina en un tiempo futuro y al imaginarse una comunidad utópica situada en una nueva dimensión espacio-temporal, Belli no sólo nos presenta una tecnología inexistente hoy en día, evocando la literatura de ciencia ficción, sino que se aproxima a la nueva frontera establecida por la escritura feminista. En este sentido, es conventiente considerar Waslala a la luz de la descripción de Penny Florence de la ciencia ficción feminista: ${ }^{3}$

Feminist S[cience]F[iction] takes women into forbidden realms. Active agency, autonomous power, the creation/adaptation of physical worlds, exploration and so forth are all in some sense transgressive for women in contemporary "developed" cultures. To imagine them for ourselves under present conditions, women have a great deal of internal and external censorship to overcome. (79)

\footnotetext{
3 Hay varios aspectos de la novela que la relacionan con la ciencia ficción: La evocación de la utopía en contraste con una distopía en un tiempo futuro es, quizás el más obvio; la problematización de la ciencia y de la tecnología y sus implicaciones para los seres humanos también coloca la obra en el subgénero de la ciencia ficción; la misma falta de una identidad nacional para Faguas se corresponde conla ciencia ficción contemporánea, según Istvan Csicsery-Ronay, Jr. (223-226); también, laubicación de la utopía Waslala en una dimensión paralela a la "real” cumple con una de la características de la ciencia ficción, según Joseph D. Miller (85). Dentro de este marco general de la ciencia ficción, Belli incluye pinceladas de realismo mágico, sobre todo en la descripción del viaje por el río San Juan, y algo de lo fantástico en la referencia a la existencia de Waslala en "una ranura del tiempo".
} 
A través de Melisandra, Belli nos presenta una protagonista femenina, una mujer "de acción”, que toma la decisión de ser independiente y de asumir una misión de alcance personal y colectivo (Gómez 40-41). Melisandra se lanza, de hecho, a la exploración del interior de su país, empresa que trae a la mente las expediciones de los exploradores europeos, narradas principalmente desde una perspectiva masculina. A la luz de lo transgresivo de este tipo de aventura para las mujeres de las sociedades “desarrolladas”, según la formulación de Florence, llama aún más la atención la osadía de mujeres como Melisandra y Engracia, la líder de los comunitaristas, en Faguas.

Aunque Waslala parece ser una novela feminista por la heroicidad y el liderazgo de sus personajes femeninos, el hecho de que Belli opte por no problematizar el tema del género crea ambigüedad en cuanto al planteamiento de una crítica feminista ortodoxa. En cierto modo, al situar su obra en el futuro, Belli puede dar por vencidos los obstáculos a que se enfrentan las mujeres de la actualidad. Según se observa en su obra, la joven protagonista tiene por modelos a dos mujeres fuertes o, en otras palabras, a dos líderes respetadas por todos los miembros de la sociedad. En la zona del río, Melisandra es reconocida como la heredera de una gran figura matriarcal, su abuela María del Río. Gracias a este reconocimiento, Melisandra goza de una autoridad especial, y es respetada al mismo tiempo por su destreza física, por su capacidad de organización, por su intuición y por su fuerza de voluntad. En Cineria, Melisandra conocerá también a otra mujer excepcional, Engracia, figura imponente por su tamaño, por su liderazgo, por su energía y por su voluntad (Gómez 44-45). Si estas mujeres encuentran alguna oposición a sus proyectos, ésta no se basa en su condición de mujeres.

La sexualidad femenina, ya sea hetero-u homosexual, tampoco se problematiza. En la obra se presentan las relaciones amistosas y amorosas de Melisandra con el periodista norteamericano Raphael, y las de Engracia con el científico norteamericano de la misma nacionalidad, Morris. Son relaciones que se caracterizan por el deseo, el respeto mutuo, el amor y la amistad. De igual forma, la relación existente entre las dos holandesas, Krista y Vera, que acompañan a Melisandra y a los demás viajeros al interior de Faguas, es del mismo estilo, con la excepción de que ellas son lesbianas. Lo único que llama la atención en cuanto a ellas es que en Holanda viven en una "matria", una comunidad poblada solamente por mujeres y niños. Este modo de vida es reconocido como una opción entre las muchas que aparecen en la novela, aunque si bien el tratamiento de Belli implica que ella no considera la "matria" como un modelo para todos, dado su carácter excluyente. Al igual que hace con los personajes femeninos principales, Melisandra y Engracia, Belli no problematiza la sexualidad de Krista y Vera, ni tampoco muestra situaciones conflictivas en las que los fagüenses se enfrenten a las holandesas por la orientación sexual de éstas. 
La condición de Faguas como entidad marginal y como algo contaminado implica que queda fuera de otro espacio puro, utópico, el que ha definido para sí el "primer mundo". En cierto modo, las sociedades más ricas y avanzadas del mundo, al asegurar su propio bienestar, en parte alejándose de las sociedades más pobres y problematizadas, han cometido el mismo error que los fundadores de Waslala. Al dejar ese primer mundo esencialmente fuera de su narración, Belli le da vuelta a la tortilla. La presencia de figuras como Rafael, el científico Morris, las holandesas Krista y Vera, y el alemán, Hermann figuras que quedan convertidas y convencidas de los valores humanos de los fagüenses, repite una estrategia que se encuentra en las narraciones utópicas, según la crítica Carol Pearson. De acuerdo con Pearson, "the most common plot structure of the feminist utopian novel is the conversion story in which a male narrator comes to see a feminist society as superior to a male-dominated one" (59). Algo parecido ocurre con los extranjeros que llegan a la tierra descrita como cuerpo "poscolonizado" y, en este caso, explotado y abandonado. Los personajes norteamericanos y europeos son estos conversos que perciben algo positivo en Faguas que no pueden encontrar en sus propias culturas, como ha afirmado Laura Barbas Rhoden (4). Se trata de la amistad, la solidaridad, la valentía y el sacrificio. El periodista norteamericano Raphael, el converso más reciente, reflexiona:

el viaje se había convertido para él en un redescubrir la inagotable capacidad de la especie para adaptarse a situaciones adversas sin perder la esencia, el deleite de ser. Desde las comodidades de Nueva York se juzgaba con no poco horror y lástima a los habitantes de estas regiones exóticas y olvidadas, marginados de la producción y consumo de bienes materiales. Era imposible, desde allí, percibir las compensaciones de esta vida desprovista de abundancia; apreciar, por ejemplo, lo reconfortante y agradable que era sentir una mayor dependencia de la relación con otros seres humanos, tener que apoyarse en el afecto, en la mutua noción de vulnerabilidad, en la solidaridad colectiva. Hasta para entretenerse dependían aquí los unos de los otros

La misma Melisandra, que había sentido una fascinación por los productos de los países “civilizados” e incluso había llegado a la utópica Waslala, decide que su primer compromiso es con el pueblo de Cineria.

A pesar del retrato algo desagradable que pinta Belli de Cineria, su protagonista Melisandra y el periodista norteamericano Raphael descubren allí una vitalidad y ciertos valores humanos, tales como la amistad, la solidaridad, la creatividad, la valentía y el sacrificio. Al elegir dedicarse a la reconstrucción de Cineria, con plena conciencia de los problemas que ésta acarrea, Melisandra y Raphael afirman el sentido y el valor de la lucha por una sociedad mejor. Sus recursos principales no 
son materiales; han de recurrir al espíritu infatigable del pueblo, a la esperanza y a su capacidad de imaginar un Faguas digno de sus habitantes. Aunque John Beverley ha observado que lo subalterno normalmente refleja la experiencia del pueblo, de los desaventajados, y no la de la elite (11-12), Belli afirma la posibilidad del acceso a lo subalterno por parte de "los conversos”, a pesar de sus orígenes sociales, con tal de que se comprometan con el pueblo. ${ }^{4}$

La novela de Belli nos ofrece una revaloración de "la barbarie” al mismo tiempo que margina a “la civilización”. La síntesis que hace Walter Mignolo de las teorías feministas y la teoría post-colonial nos ayuda a entender el planteamiento de Gioconda Belli en Waslala. En cierto modo, Belli inicia la narración de su novela entre "la civilización” y "la barbarie". El movimiento de los personajes principales hacia el interior de Faguas acarrea el traslado del punto de vista a "la barbarie". La narración asume la perspectiva de una sociedad y una nación que no es árbitro de su destino y que enfrenta graves problemas para su supervivencia. Siguiendo la formulación de Mignolo, se podría decir que Belli participa en una respuesta al discurso de "la civilización” por parte de "la barbarie":

Thus, the organic intellectuals of the Amerindian social movements (as well as Latino, Afro-American, and women) are precisely the primary agents of the moment in which "barbarism" appropriates the theoretical practices and elaborated projects, engulfing and superceding the discourse of the civilizing mission and its theoretical foundations. (299)

Sin rechazar los aspectos de "la civilización” europea y norteamericana en que los intelectuales latinoamericanos pueden reconocerse o considerarse co-partícipes, Belli formula no sólo la identidad y la agencia de las comunidades subalternas de Latinoamérica, sino que propone a estas comunidades como alternativas vitales y humanas a las sociedades hegemónicas.

La esperanza con que termina la novela se corresponde con la nueva interpretación que Mignolo le da a la formulación decimonónica de la lucha entre "la civilización” y "la barbarie”. El debate ya no pertenece a la frontera como el

4 El tipo de liderazgo que ejercen varios personajes tales como Engracia, Morris, y luego Raphael y Melisandra, puede reflejar el hecho de que Gioconda Belli misma se acerco a la lucha revolucionaria desde una experiencia de privilegio social y económica. Este puede ser uno de los puntos en que Belli se siente cerca de Gramsci, por quién expresa admiración en una entrevista realizada por Yazmín Ross y publicaca en la revista semanal Brecha. Aunque Gramsci teorizaba sobre los líderes intelectuales, sobre todo, reconocía la dificultad de que hubiera suficientes líderes intelectuales “orgánicos”, provenientes de las clases subalternas. Por esta razón, según Marcia Landy, Gramsci admite el papel transicional de los líderes que se identifican con las clases subalternas para romper con los patrones del pensamiento tradicional y para cultivar a los intelectuales “orgánicos” del futuro (30-31). 
"espacio vacío”, sino a la idea de frontera como "borderlands”. ${ }^{5}$ Según Mignolo, "the location where a new consciousness, a border gnosis, emerges from the repression subjected by the civilizing mission" (299).

Al preferir el término "borderlands", Mignolo intenta romper la fatídica oposición de "civilización vs. barbarie”, lo mismo que trata de llegar más allá de las oposiciones "dentro/fuera" o "centro/periferie”, teorizadas por otros críticos de los estudios poscoloniales o subalternos (338). Mignolo termina su Local Histories/ Global Designs con la idea del "border thinking" como un posible camino hacia un entendimiento mejor y más justo entre las culturas del mundo:

The last horizon of border thinking is not only working toward a critique of colonial categories; it is also working toward readressing the subalternization of knowledges and the coloniality of power. It also points toward a new way of thinking in which dichotomies can be replaced by the complementarity of apparently contradictory terms. Border thinking could open up the doors to an other tongue, an other thinking, an other logic superseding the long history of the modern/ colonial world, the coloniality of power, the subalternization of knowledges and the colonial difference. (338)

Gioconda Belli tampoco se queda en la descripción de Faguas como barbarie, distopía o sociedad irremediablemente subalterna, sino que busca también resolver las estructuras oposicionales a base de la agencia de sus protagonistas. Paradójicamente, es en el distópico Faguas que los personajes de Europa y Norteamérica encuentran más sentido en la vida. Al hacer que los viajeros, sobre todo Melisandra y Raphael, "se conviertan" y se comprometan con Faguas en cuanto distopía, y al hacer que Melisandra elija Cineria por encima de la utópica Waslala, Belli reivindica ciertas cualidades y habilidades humanas que encuentra en los personajes identificados con lo subalterno, tales como la vitalidad y el disfrute de la vida, una sensibilidad hacia la maravilla o el milagro, la adaptabilidad a las circunstancias, la capacidad de aguantar el sufrimiento, la solidaridad, la interdependencia, y la apertura hacia el encuentro con el otro. Estas cualidades se han perdido en lo poco del mundo "civilizado" que se deja entrever en la obra. Al mismo tiempo, el ideal utópico de

5 Al referirse a la problemática de civilización y barbarie en el siglo xix, sobre todo en Argentina y en Estados Unidos, Mignolo cita el pensamiento de José Pedro Barrán, sobre todo con respecto a la idea de "la frontera/the frontier" como un espacio vacío o carente de pobladores representativos de los valores europeos. A continuación, Mignolo se basa en el concepto de "borderlands" formulado por Gloria Anzaldúa. La esperanza que crea Belli al final de la novela enlaza de nuevo con el pensamiento de Gramsci, según lo interpreta Renate Holub. Holub afirma que Gramsci reconocía la legitimidad de que el pueblo usara de la fantasia para imaginarse un mundo mejor, Este uso de la imaginación forma parte del nacimiento de la voluntad de cambio y de liberación (112-113). 
los fagüenses, sean los que sean sus orígenes, está arraigado en la imaginación del pueblo y mantiene viva la esperanza del pueblo en una realidad distópica.

\section{BiBLIOGRAFÍA}

Anzaldúa, Gloria. Borderlands/La Frontera. The New Mestiza. 2. San Francisco: Aunt Lute Books, 1999.

Barbas Rhoden, Laura. "Greening Central American Literature". Isle: Interdisciplinary Studies in Literature and Environment 12/1 (2005 Winter): $1-17$.

Belli, Gioconda. Waslala. Buenos Aires: Emecé, 1996.

Beverley, John. Subalternity and Representation. Arguments in Cultural Theory. Durham: Duke UP, 1999.

Burwell, Jennifer. Notes from Nowhere. Feminism, Utopian Logic, and Social Transformation. Minneapolis: U of MP, 1997.

Csicsery-Ronay, Jr. "Dis-Imagined Communities: Science Fiction and the Future of Nations". Edging into the Future. Science Fiction and Contemporary Cultural Transformation. Veronica Hollinger y Joan Gordon, eds. Philadelphia: Philadelphia Press, 2002. 217-237.

Droscher, Barbara. "Huérfanas y otras sin madre". Revista de Crítica Literaria Latinoamericana 30/59 (2004): 267-95.

Florence, Penny. "The Liberation of Utopia or Is Science Fiction the Ideal Contemporary Women's Form”. Plotting change: Contemporary Women's Fiction. Linda Anderson, ed. Londres: Edward Arnold, 1990.

Gil Iriarte, María Luisa. "Waslala: reescritura femenina de la utopía". <www. cervantesvirtual.com/servlet/SirveObras/3719032276973626591435/p000005. htm>

Gómez, Ruben L. "La mujer en la reconstrucción de la sociedad nicaragüense según G. Belli en Waslala". Middle Atlantic Council of Latin American Studies (Abril 2000): 39-46.

Guha, Ranajit \& Gayatri Chakravorty Spivak. Selected Subaltern Studies. Nueva York: Oxford UP, 1988. 35.

Holub, Renate: Antonio Gramsci: Beyond Marxism and Postmodernism. Londres: Routledge, 1992.

Jameson, Fredric. The Seeds of Time. Nueva York: Columbia UP, 1994.

Landy, Marcia. Film, Politics and Gramsci. Foreword by Paul Bové. Minneapolis:

U of Minnesota P, 1994. 
Martin, Victoria. Textual Spaces and Their Political Implications in Gioconda Belli's La mujer habitada and Waslala. Dissertation. University of North Carolina at Chapel Hill, 1999.

Miller, Joseph D. “Popes or Tropes: Defining the Grails of Science Fiction”. Science Fiction, Canonization, Marginalization, and the Academy. Gary Westfahl y George Slusser, eds. Westport, CT: Greenwood Press, 2002. 79-87.

Mills, Sara. "Post-colonial Feminist Theory". Feminist Readings/Feminists Reading. 2nd Ed. Sara Mills y Lynne Pearce, eds. Londres: Prentice Hall, 1996.

Mignolo, Walter D. Local Histories/Global Designs. Coloniality, Subaltern Knowledges, and Border Thinking. Princeton: Princeton UP, 2000.

Pearson, Carol. "Women's Fantasies and Feminist Utopias". Frontiers: A Journal of Women's Studies 2/ 3 (1977): 50-61. Citada en Utopian and Science Fiction by Women: Worlds of Difference. Jane L. Donawerth y Carol A. Kolmerten, eds.

Rodríguez, Ana Patricia. "Memorializing the Past and Future in Central America: Gioconda Belli's Waslala”. Paper presented at Latin American Studies Association (March 16-18, 2000).

Ross, Yazmín. "Entre la nada y la utopía: Gioconda Belli y sus presagios”. <www. elcastellano.org/gioconda.html> 